\title{
Vacuum methods of surface treatment with subnanometer roughness
}

\author{
Yury Panfilov ${ }^{1, *}$, and Leonid Kolesnik ${ }^{1}$ \\ ${ }^{1}$ MSTU named after Bauman, Electronic Technology in Machinery Chair, 105005 Moscow, 2-d \\ Baumanskay St., 5, Russia
}

\begin{abstract}
Vacuum methods of surfaces with $1 \mathrm{~nm}$ or less roughness treatment were analyzed.Physical models of super sleek surfaces polishing into vacuum cambers by means of ion beam etching and thin film deposition and ion cluster treatment were shown.The results of experimental research of ion cluster polishing with differentregimes were represented.Prospects of surface treatment with subnanometer roughness by means of vacuum methods are represented.
\end{abstract}

\section{Introduction}

Very high claims are produced to surfaces roughness and layers disturbed depth of microand nano-electro-mechanical systems and mirror of laser gyroscopes and nano-electronic devices as well. Even nano-format surfaces distortion can operate of handsome influence to any physical properties of products.

Therefore, now certain confine of one nanometer roughness take place and realization of that confine connects with fundamental limits with outlook possibility of treatment and with outlook possibility of modern measurement instruments (one nanometer equal 3 or 5 atom layers, so advertising statements about so-called realized angstrom roughness are not more than the shot to act out of desire to positivism).

It is impossible to reach up of roughness desire level by means of abrasive treatment with small dispersion (diamond) polishing-pastes because minimal diameter of abrasive particle is more than one nanometer. Deep disturbed layer with polishing materials contamination take place after electro-chemical or electro-mechanical finish treatment and lapping. The next levels of roughness can be reached up by means of mechanical treatment: $\mathrm{R}_{\mathrm{a}}=200-400 \mathrm{~nm}$ (grinding), $\mathrm{R}_{\mathrm{a}}=20 \mathrm{~nm}$ (polishing) andR $\mathrm{R}_{\mathrm{a}}=1-2,5 \mathrm{~nm}$ (diamond turning) $[1]$.

It is possible to reach up of roughness minimal level by means of successive using of chemistry-mechanical and corpuscular-beam (vacuum ion-beam and ion-cluster [2]) methods of surface polishing.

However, up to date don't clearly the minimization limit of surfaces roughness by means of vacuum methods of treatment. So, the aim of this article is to analyze of modern vacuum methods for sub-nanometer surfaces roughness realization.

\footnotetext{
${ }^{*}$ Corresponding author: panfilov@bmstu.ru
} 


\section{Vacuum methods for super-smooth surfaces manufacturing}

Ion-beam polishing is based on surface micro-roughness sputtering effect and defect layer removing. So, surface properties become such as bulk material properties. The scheme of accelerated ions impact to rough surface and atoms material sputtering and microroughness smoothing $\left(\mathrm{h}_{2}<\mathrm{h}_{1}\right)$ is represented at Fig. 1. Surface roughness parameter $\mathrm{R}_{\mathrm{q}}=0,25-0,5 \mathrm{~nm}$ can be produced by means of ion-beam polishing method [3].

The essential lack of ion-beam polishing is the sputtering speed difference of surface micro- and macro-defects such as pores, scratches, dust and chemical contaminations.

For this lack removal, thin film is deposited on surface before ion-beam polishing. Such operation is named "surface planning". Ion polishing with surface planning method consists of the same material thin film deposition and ion-beam etching of surface with thin film after that. The ion-beam etching depth is about two times more than the deposited thin film thickness. Thin film deposition and ion-beam etching are repeated many times with decreasing of thin film thickness every time. Surface roughness parameter $R_{q}=0,25-0,5$ $\mathrm{nm}$ can be produced by means of ion-beam polishing with surface planning method [3,4].
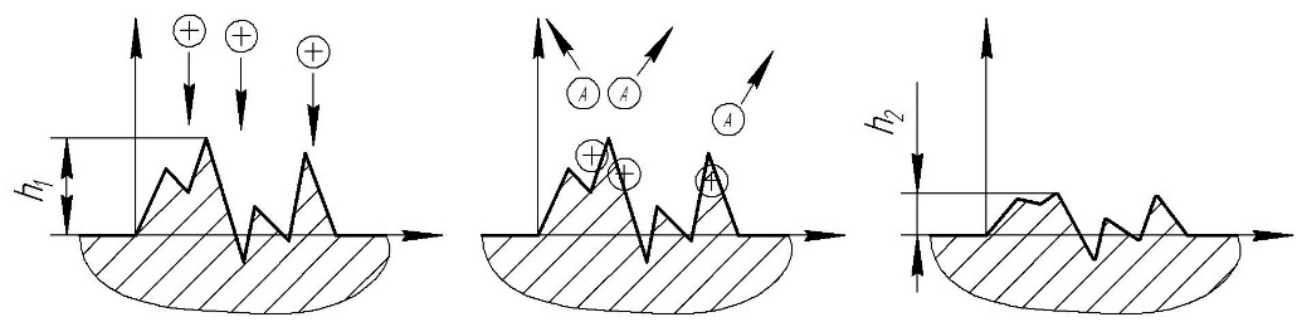

Fig. 1. Scheme of surface micro-roughness smoothing by means of ion bombardment.

A number of glassceramics sirface relief researches before ion beam etching and after ion beam etching as well were carried out by means of atomic force microscope SolverNext. Ion beam energy was $500 \mathrm{eV}$ and angle between ion beam direction and substrate sirface was $20^{\circ}$ or $90^{\circ}$ (Fig. 2. and Fig. 3.)

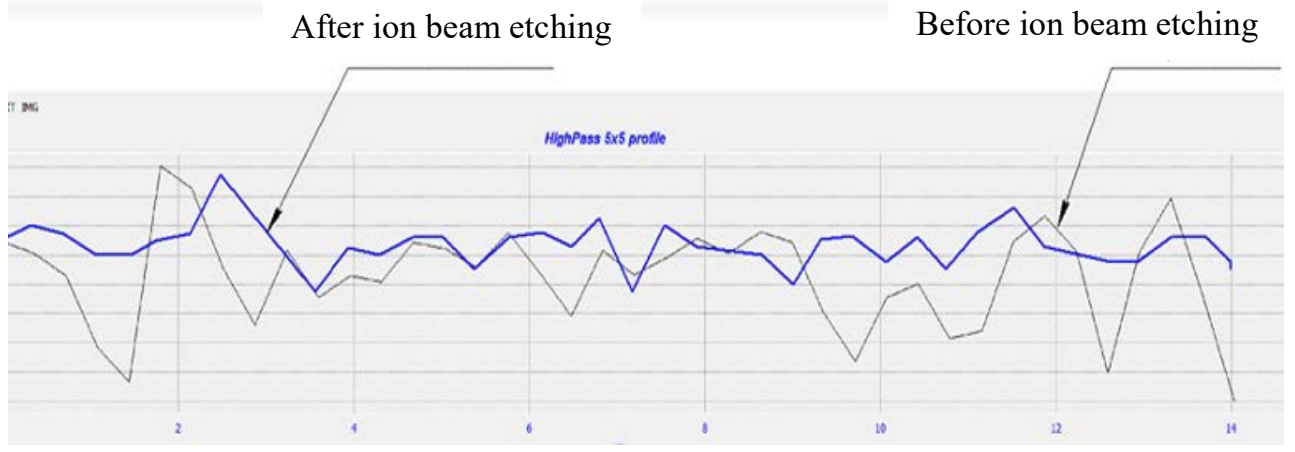

Fig. 2. Glassceramics sirface relief map before ion beam etching and after ion beam etching with $20^{\circ}$ angle 


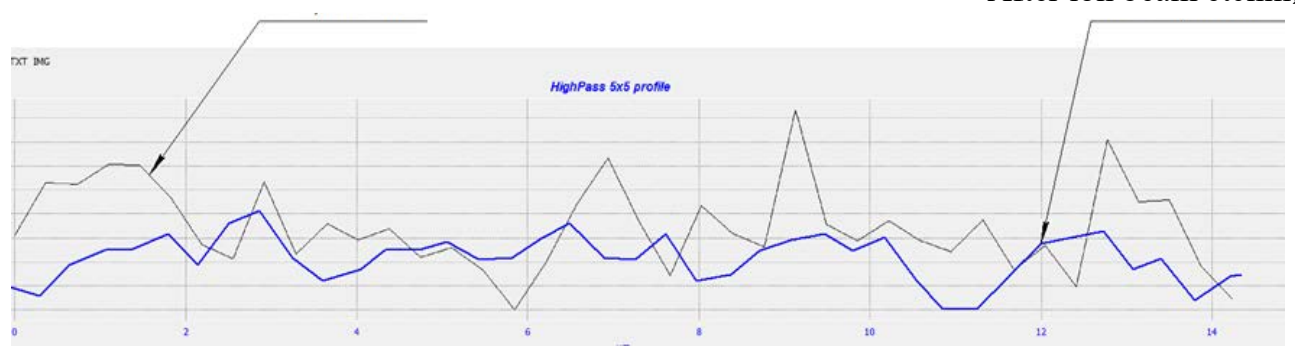

Fig. 3. Glassceramics sirface relief map before ion beam etching and after ion beam etching with $90^{\circ}$ angle

The results of this experiments show that glassceramics sirface micro relief after ion beam etching with $20^{\circ}$ angle is smoother than glassceramics sirface micro relief after ion beam etching with $90^{\circ}$ angle. Beside this, ion beam polishing method has an essential limitation in etching of sirfaces with microdefects and microcontaminations because of different etching rate of different surface area etching.

The scheme of the ion polishing with surface planning $\left(\mathrm{h}_{3}<\mathrm{h}_{2}<\mathrm{h}_{1}\right)$ is represented at Fig.4.
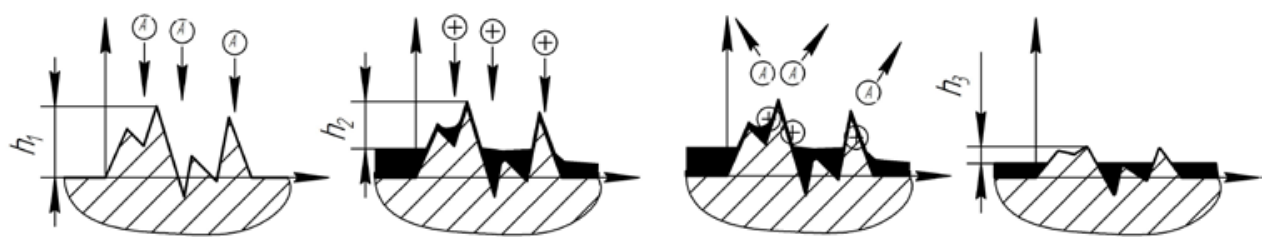

Fig. 4. Scheme of the ion polishing with surface planning.

Like ion-beam polishing else plasma chemical polishing is applied for surface roughness decrease. Plasma chemical polishing method is based on chemical reaction between reactive gas disturb layer because uniform low temperature and high density plasma is used. Surface roughness parameter about $\mathrm{R}_{\mathrm{q}}=0,8 \mathrm{~nm}$ can be produced by means of plasma chemical polishing method [5]. The lacks of this method are etching high selectiveness and toxic gas using.

One of the promising methods of a surfaces vacuum treatment is ion-cluster surface polishing [2]. By means of ion-cluster surface polishing can obtain super smooth surfaces with material structure conservation of practically any materials, even super-hard materials. Surface roughness parameter $\mathrm{R}_{\mathrm{a}}=0,6-1,3 \mathrm{~nm}$ can be produced by means of ion-cluster polishing method [2]. Unfortunately, now there is not the industry equipment for surface ion-cluster treatment at world market.

The scheme of the ion-cluster polishing of surface $\left(\mathrm{h}_{2}<\mathrm{h}_{1}\right)$ is represented at Fig.5. 

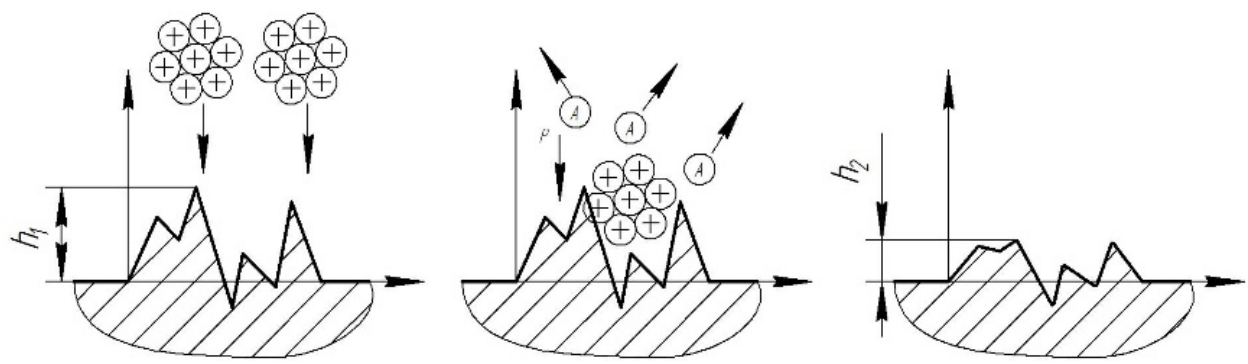

Fig. 5. Scheme of the ion-cluster polishing.

The main difference between ion beam and ion cluster polishing repose in numbers of atoms in cluster which simultaneously clash with the same numbers of atoms on solid surface.

Kinetic energy of the cluster atoms less than kinetic energy of the cluster, so the depth of penetration of every atom to solid surface is very small.

Impact of ion cluster on surface is accompanied with more high energy in comparison with impact of individual ion. The increase of ion cluster's dose of radiation leads to surface polishing and to improve the surface quality of all materials practically. In spite of high coefficient of sputtering, very small layer of surface material is removed.

Ion clusters can be also used for surface cleanning and etching, for thin film deposition and new materials syntesis, for ion implantation and high moleculs materials epitaxy.

Ion clusters can be generated by different methods with differention materials, electical charge, intensity, energy and so on. The comparative characteristics of surfaces before ion cluster treatment and after $\mathrm{CO}_{2}$ ion cluster polishing of $\mathrm{ZnO}$ thin films with $30 \mathrm{keV}$ energy and different radiation doses are represented on Fig. 6 [3].

\section{Results of the polishing vacuum methods research}

Results of the surfaces ion-beam polishing and ion-beam etching with surface planning research are represented in $[4,5]$. Comparative dates of the direct ion-beam etching and ion-beam etching with surface planning of the samples with the same initial roughness are discussed. The results demonstrate that surface roughness parameter $R_{a}=0,25-0,5 \mathrm{~nm}$ and surface defects decreasing as well can be obtained by means of the ion-beam polishing method with surface planning. Nevertheless, there are not a word about method of nanorelief measurement, square of measurement and a number of measurements (reliability) in the articles.

Surface planning is a process of sample surface cavity filling by means of ion sputtering of a target from the same material as sample material [5]. Such process gives opportunity to decrease of quartz sample roughness in two times (up to $R_{a}=0,8 \mathrm{~nm}$ ) and to create chemical clean surface without any defects. The results of quartz glass polishing by means of such gas as $\mathrm{SF}_{6}, \mathrm{Ar}$ or $\mathrm{O}_{2} \mathrm{RF}$ plasma are represented in $[6,7]$. 
(a) before irradiation, $\mathrm{R}_{\mathrm{a}}=16.1 \mathrm{~nm}$

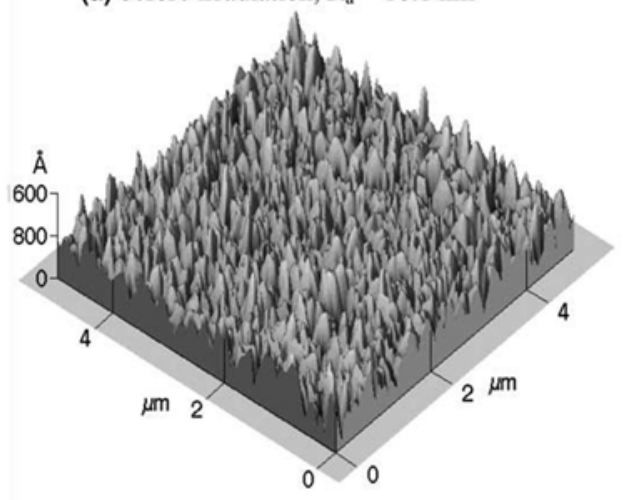

(c) irradiated $5 \times 10^{15}$ clusters $/ \mathrm{cm}^{2}, \mathrm{R}_{\mathrm{a}}=2.8 \mathrm{~nm}$

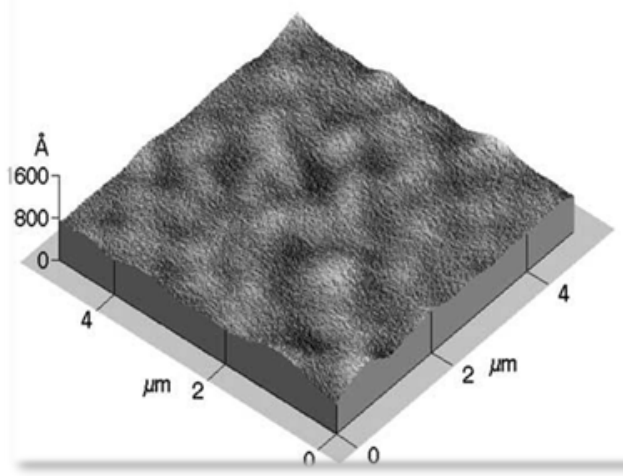

(b) irradiated $5 \times 10^{i 4}$ clusters $/ \mathrm{cm}^{2}, \mathrm{R}_{\mathrm{a}}=11.6 \mathrm{~nm}$

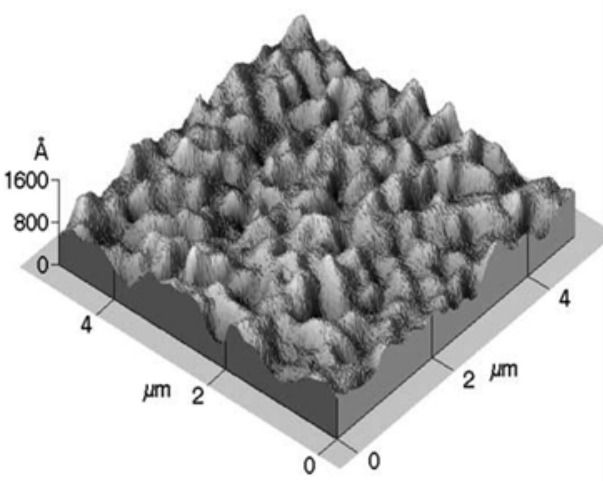

(d) irradiated $1 \times 10^{16}$ clusters $/ \mathrm{cm}^{2}, \mathrm{R}_{\mathrm{a}}=0.9 \mathrm{~nm}$

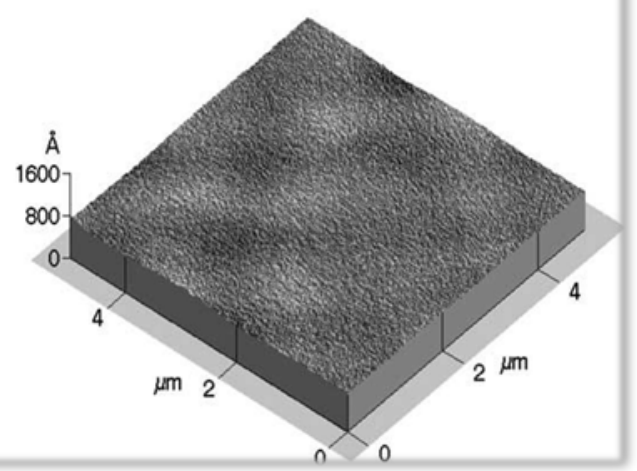

Fig. 6. The comparative roughness parameters $R_{a}$ of surfaces before ion cluster treatment (a) and after $\mathrm{CO}_{2}$ ion cluster polishinig of $\mathrm{ZnO}$ thin films with $30 \mathrm{keV}$ energy and different radiation doses: $5 \cdot 10^{14}$ clusters $/ \mathrm{cm}^{2}$ (b), $5 \cdot 10^{15}$ clusters $/ \mathrm{cm}^{2}$ (c), $1 \cdot 10^{16}$ clusters $/ \mathrm{cm}^{2}$ (d).

\section{Conclusion}

The obtainment of surfaces with roughness parameter about $\mathrm{R}_{\mathrm{a}}=1 \mathrm{~nm}$ and less is the actual task for modern optics, micro- and nano-electronics, micro- and nano-mechanics. The best surface treatment method for minimum roughness level obtaining look-out prosecutes in the number of countries. Among the methods are the worst requirement methods: ion-beam and ion-plasma etching, plasma chemical polishing. They give opportunity to polish of surfaces with roughness parameter about $\mathrm{R}_{\mathrm{a}}=1 \mathrm{~nm}$ and less and with high level of chemical clean and without defect layers of the surfaces. With our viewpoint, the combination of ionbeam polishing with surface planning and ion-plasma etching methods in unified vacuum cycle is more perspective for surfaces treatment with subnanometer roughness (method of ion-plasma polishing is also promising).

\section{References}

1. V. Gorohov, E. Zaharevich, M, Skvortsova, The increasing of metal-optic fittings precise by diamond turning on ultraprecise tools, Photonics, № 1, P. 118 - 123 (2014) 
2. A.E. Zarvin, Cluster beam in rare gas: from science to technology, Report book of XXII Science and Technical Conference "Vacuum science and technic", M.: 2015, P. $39-41$

3. H.Chenetal. NIMB, V. 241, p. 630

4. F. Frost, R. Fechner, B.Ziberi, J.Vollner, D. Flamm, A. Schindler, Large area smoothing of surfaces by ion bombardment: fundamentals and applications, J. Phys.: Condens. Matter 21224026 (20pp) (2009)

5. A.I. Stogniy, N.N. Novitskiy, O.M. Stukalov, Ion-beam polishing of the nanosize relief of an optic materials surface, Letters to GTF, V.28, Issue 1 (2002)

6. Yilong Wu, Weiguo Liu, Lingxia Hang, Research on RF-generated Plasma Polishing, Physics Procedia 32, 590 - 597, 1875-3892 (2012)

7. Yuan Tian, Weiguo Liu, Lingxia Hang. Influence of Oxygen Flow Rate on the Variation of Surface Roughness of Fused Silica during Plasma Polishing Process. Physics Procedia 18, 107-111, 1875-3892 (2011) 